\title{
Once poetas argentinos
}

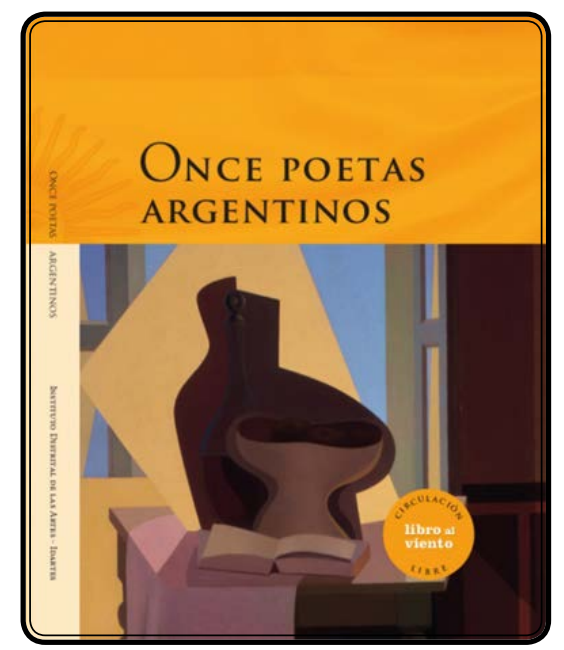

Once poetas argentinos. 2018. Selección y prólogo de Susana Szwarc. Colección Libro al viento. Bogotá. Este libro fue publicado con el apoyo del Ministerio de Relaciones Exteriores y Culto de la República Argentina, el Ministerio de Cultura de la República Argentina y la Embajada de Argentina en Colombia, como parte de las actividades de Argentina, invitado de honor a la XXXI Feria Internacional del Libro de Bogotá 2018.

\section{Una polifonía inconclusa}

Cada vez que surge una antología se piensa en un mapa que sea capaz de registrar el territorio en su totalidad o, quizás, se intenta trazar una coreografía concebida por una escritura en movimiento que acompañe los pasos de la danza. Desafío imposible de alcanzar y que de manera casi inevitable termina deslizándose hacia una obra inconclusa.

Por otra parte, en cada oportunidad que se da de leer poesía, que se efectúa una entrega de ella, se trata sobre todo de brindar un don, el don implícito de todas las expresiones artísticas (de allí el agradecimiento). Sabemos que, como marca indeleble, en una antología es más lo que queda por fuera de ella que lo que se incluye. Por tal razón este prólogo intentará revertir algo de esta situación, un ápice, a esta condición inevitable. Y el antólogo (la antóloga) -que bien podría ser un personaje de Kafka, como el cartógrafo que realiza el mapa del imperiodescarrilla en una tarea imposible. En medio de este reconocimiento de los límites, trataremos de avanzar.
Una enorme heterogeneidad ha marcado a la poesía argentina desde las vanguardias de comienzos del siglo XX. Si bien el estridentismo mexicano, el creacionismo de Huidobro o las inmensas voces de Vallejo y del primer Neruda, como la experimentación continua del colombiano León de Greiff, muestran que este proceso ha sido un fenómeno común a toda Hispanoamérica, tal vez en Argentina esta experiencia se ha llevado a un punto difícilmente comparable con otros países de la región.

Una larga lista (por problemática que parezca) que incluya los nombres de Macedonio Fernández (1874-1952), Oliverio Girondo (18911967), Alfonsina Storni (1892-1938), Juan L. Ortíz (1896-1978), Jacobo Fijman (1898-1970), Jorge Luis Borges (1896-1986), Silvina Ocampo (1903-1993), Enrique Molina (1910-1996), Amelia Biagioni (1916-2000), Manuel Castilla (19181980), Alberto Girri (1919-1991), Edgar Bayley (1919-1990), Olga Orozco (1920-1999), Ricardo Zelayarán (1922-2010), Joaquín Gianuzzi (19242004), Roberto Juarroz (1925-1995), Francisco Madariaga (1927-2000), Raúl Gustavo Aguirre (1927-1983), Walter Adet (1931-1992), Leónidas 
Lamborghini (1927-2009), Miguel Ángel Bustos (1932-1976), Horacio Castillo (1934-2010), Hebe Solves (1935-2007), Alejandra Pizarnik (19361972), MarioMorales(1936-1978), Celia Gourinski (1938-2008), Enrique Puccia (1941-2001), Susana Poujol (1950-2009) y Néstor Perlongher (19491992) podría estar acompañada por otra similar, igualmente copiosa, que contenga otras voces, empezando por la de Lugones (1874-1938) y siguiendo por Ricardo Molinari (1898-1996) o Carlos Mastronardi (1901-1976). O incluso una tercera conformada por aquellos que nos dejaron sus inconfundibles voces hace mucho menos tiempo, como Horacio Preler (1929-2011), Juan Gelman (1930-2014), Macky Corbalán (1963-2014), Juana Bignozzi (1937- 2015), Jorge Leónidas Escudero (1920-2015), Jorge Ariel Madrazo (1931-2016), Máximo Simpson (19292016), Leonardo Martínez (1937-2016), Hugo Padeletti (1928-2018).

Sin embargo, el trazado de cualquier línea de tiempo, en lo que respecta a la poesía, induce a numerosos equívocos, el principal de los cuales es que el diálogo que hay entre sus hacedores y los lectores se van modificando de manera continua. Macedonio Fernández, queha nacidoel mismo año que Lugones, comenzó su verdadera irradiación de manera póstuma, construyendo con sus textos una contemporaneidad y una vigencia estética deconstructiva muy inusual en nuestras letras. Refiriéndose a la improbable presentación de un libro, Macedonio nos continúa transmitiendo su irreverente humor desde un misterioso presente: "Este libro viene a llenar un gran vacío...con otro".

Esta heterogeneidad de la poesía argentina se encuentra en consonancia, además, con las diversas expresiones artísticas: plásticas, musicales, dancísticas, teatrales. Hay una larga oscilación entre la innovación y lo tradicional, lo cual se observa muy nítidamente en el nombre con que Oliverio Girondo bautizó su revista de vanguardia: Martín Fierro. Y, saliendo de la frontera (o volviendo a ella), no podemos olvidar cómo el modernismo y Rubén Darío produjeron un quiebre respecto a la influencia de la poesía peninsular, con medio siglo de anticipación a lo que constituyó el modernismo brasileño.
Transcurrido caso un sigo de la aparición de las revistas Proa y Martín Fierro, todavía se percibe la larga duración de un amplio espectro experimental en la producción poética argentina, como si "la tradición de la ruptura", sobre la que reflexionará con agudeza Octavio Paz, hubiera venido para quedarse definitivamente. Las vanguardias de comienzos del siglo $X X$ fueron reinventadas en las décadas posteriores, de tal forma que nuevos grupos, muy diferentes entre sí, en sucesivos momentos, también tuvieron, la ilusión de que podían comenzar a partir de cero. Además de grupos de poetas nucleados alrededor de distintas publicaciones específicas del género, que han llegado a constituir corrientes estéticas más o menos reconocibles: Poesía Buenos Aires, Poesía=Poesía, Tarja, Último Reino, Alguien llama, Danza del Ratón, Diario de Poesía, Barataria, por citar solo algunos ejemplos, quizás ninguna de ellas ha sido tan fuerte como el caso del surrealismo en Argentina, donde en estas voces, pese a su fuerte individualidad, se constatan parentescos claramente identificables y una voluntad manifiesta de adhesión. En el proceso de "larga duración", al cual pertenecen de parte entera el lenguaje y la poesía, resulta extremadamente difícil precisar los límites y establecer las fronteras entre una corriente y otra, e incluso entre una lengua y otra. La escritura y la lectura nos llevan de paseo por las napas de la historia (hasta, hacia y en el presente en construcción). A inventar y reinventar imágenes que subvierten y redoblan la vida.

Al hablar de la poesía surrealista argentina, Miguel Espejo nos señala que "los procesos literarios, sus corrientes y movimiento [...], son ubicuos y versátiles $\mathrm{y}$, estrictamente, no pueden ser situados en terrenos muy delimitados". Ahora bien, cuando decimos poesía argentina, me pregunto, les pregunto -así como cuando nombramos cualquier otro país de nuestra Latinoamérica- ¿hablamos también de la actual poesía de los pueblos indígenas que se va desplegando en libros, revistas, antologías, y se da a reconocer tanto en español como en sus respectivas lenguas? Hay varias antologías, entre ellas la de Poesía de mujeres mapuche, selknam y yámana, realizada por el poeta Cristian Aliaga y que publicó Ediciones Desde la Gente en el 2010. 
En el 2008 el Instituto de Cultura del Ministerio de Educación del Chaco creó una colección de libros de autores indígenas. Un ejemplo es Ecos de la resistencia; Pajlhayis Kajiayayaj Pak, de Audencio Zamora Leckott (edición en castellano y wichí).

En esta antología de Once poetas argentinos, que se publica con motivo de ser nuestro país el invitado de honor de la Feria Internacional del Libro de Bogotá, resuena el significante once, un número que se presta a interpretaciones cabalísticas, a las que era aficionado Borges. La cábala tiene numerosos vasos comunicantes con el "azar objetivo" de los surrealistas. Es en estas tierras atravesadas por inmigrantes de caso todos los lugares del planeta, más las voces indígenas y criollas, donde Aldo Pellegrini constituye el primer grupo surrealista de América Latina, en 1926, apenas un par de años después de que se publicara el célebre manifiesto de Breton. El conocimiento del manifiesto les llega a este grupo de jóvenes por una revista de medicina, lo cual nos revela que las llamadas vanguardias se improvisaron, en sus orígenes, mucho más que cuando posteriormente se decantaron. Una mujer, entre muchas otras, fue participe de este grupo y continuó su vida entera escribiendo: María Meleck Vivanco (1921-2010). Transcribo un fragmento de un poema suyo (y quisiera de cada poeta poner poemas):

\section{[...]De una ciudad a otra, profetizaba grandes diluvios blancos \\ Incendios reflejados en \\ palmares ocultos \\ Había un caballo hermoso que misteriosamente me seguía \\ Como la lluvia \\ voluptuosa en mi camisa, que desgranaba un girasol de ruidos \\ No convenía ilusionar entonces \\ Los pies desnudos sobre púas [...]}

Con el número once algunos podrán pensar de inmediato en un equipo de fútbol, pero en lugar de once individuos arrojados tras una pelota, son once poetas arrojados a página nunca completamente blanca. El entramado del fútbol y la cultura popular argentina es inextricable. Poco después de la muerte de Borges se le preguntó a un hombre de la calle qué significaba para él este poeta. Su respuesta futbolera es también de antología: "Borges es el Maradona de la literatura".

Siguiendo con el once comprobamos que el verso endecasílabo, prestado del italiano, fue de un uso privilegiado en nuestro idioma desde la época de Garcilaso de la Vega (no en esta ocasión el "Inca") y ha llegado con vitalidad hasta fines del siglo XIX, poco antes de que las vanguardias propusieran, a nivel planetario, el fin del reinado de los cánones y de las preceptivas tradicionales.

El significado del once se multiplica por doquier: es, entre tantas cosas, el primer número primo de dos cifras. Para el tarot, el arcano mayor 11 representa la fuerza, la creación, elementos centrales de la expresión poética. En la cábala se relaciona con la letra kaf (כ); (Kaph, palma de la mano que se vincula a koah, fuerza). Y otras fórmulas aconsejan, a los poseedores de ese número, evitar el gasto de energía en empresas insensatas. Ya Mallarmé hablaba de la insensata tarea de escribir, proponiendo con Un golpe de dados un modo de asociar el lenguaje y el azar a la imposible tarea de nombrar el universo.

Podríamos recordar también a Karl Marx y sus tempranas y célebres Tesis sobre Feuerbach, donde tan bien nos mostraría que esa división, esa dicotomía entre naturaleza y sociedad, llevaría a formas canallescas de "naturalizar" las sobreexplotaciones. En su tan conocida tesis número once dice: "Los filósofos no han hecho más que interpretar de diversos modos el mundo, pero de lo que se trata es de transformarlo".

La referencia a Marx no es caprichosa. Nuestra poesía estuvo surcada por la cuestión social. Los famosos grupos de Florida y Boedo, que interpretaciones posteriores les asignaron roles definitivos y antagónicos, cuando había varios de ellos que frecuentaban a ambos (y especialmente se puede subrayar el nombre de Raúl González Tuñón), muestran que el debate entre una poesía preocupada exclusivamente por cuestiones subjetivas y/o estéticas y otra que trataba de expresar el "dolor social" por las circunstancias de los desfavorecidos de nuestra 
sociedad, se ha prolongado, bajo otras formas lingüísticas, hasta nuestros días. Juan Gelman diferenció perfectamente filosofía de poesía, y en el poema "Confianzas" nos expresaba:

"con este poema no tomarás el poder" dice "con estos versos no harás la Revolución" dice "ni con miles de versos harás la Revolución" dice se sienta a la mesa y escribe.

Y once también es, en inglés, "una vez". Volviendo después de estas divagaciones a las que siempre induce la numerología, al campo poético que nos corresponde. Tenemos nuestros once poetas. Vivos. Entre ellos me incliné por un recorte de los que nacieron entre $1945 \mathrm{y}$ 1955, salvo Liliana Ancalao que lo hizo en 1960, es decir, pertenecientes a una generación o dos posteriores a los autores mencionados al comienzo, que marcan el principal entramado sobre el cual se ha desarrollado toda la poesía argentina del siglo XX, con excepciones como la de Antonio Porchia (1885-1968), considerado por André Breton "la mayor expresión poética de la lengua española".

Todos ellos escribieron en democraciadictadura-democracia y, en su mayoría, escribieron ya lo principal de su obra poética. Sobre ellos, precisamente, prefiero no hablar, en principio porque los lectores pueden juzgar y descubrir por sí mismos sobre la riqueza y el valor de estas voces diversas, pero también porque de ese modo puedo al menos citar algunos de los muchos nombres que quedaron fuera de esta antología. Tampoco estas menciones pueden ser exhaustivas, por la naturaleza misma de este prólogo, que quiere ser más una invitación que una explicación.

El poeta no está afuera de su contexto, aunque está allí de un modo distinto al de un narrador. Hay una parte de él, como nos enseñara John Berger, que es atemporal, pues el poeta está esencialmente vinculado al idioma que lo contiene y a algo que lo hace escapar de alguna manera a aquello que lo rodea. Está alternativamente adentro y afuera, porque habla de la condición humana en lo que ella tiene de más huérfana y desnuda.
Antonio Requeni (1930) posee una larga trayectoria que ha merecido numerosos reconocimientos desdesus primeras publicaciones en la década de 1950, hasta su reciente antología La palabra en el tiempo (2017), publicada en España. Mucho antes, el escritor y notable cineasta Edgardo Cozarinsky había sostenido que

La prodigiosa capacidad de lirismo que alienta en la poesía de Antonio Requeni es de las más inesperadas. He aquí a un poeta que no teme hacer suyos los temas de la gran poesía lírica universal y afronta esa riesgosa confrontación para hablarnos de la infancia perdida, del amor soñado y vivido, de la amistad o de la música, no solo con acento personal sino con poderosa, inconfundible sinceridad.

La llamada Generación del 60 introdujo en nuestra poesía un tono conversacional que había existido antes de ella. La mayor parte de estos intentos de prosificar el verso no sobrevivieron a la usura del tiempo, pero aportaron un indiscutible tono que se notó especialmente en la región del Río de la Plata y de Buenos Aires. Horacio Salas (1938) y Alberto Szpunberg (1940) participaron de la revista El Barrilete. Mario Goloboff ha resumido bien los distintos elementos que componen la creación poética de Salas:

La intertextualidad actúa en [sus] poemas como una vertiente interior y necesaria. Ginsberg, Neruda, Borges, no son citados ni en función de semejanza ni de contradictoriedad; son reelaborados a la luz de una nueva experiencia. Los múltiples discursos de la publicidad, de los medios de difusión y de confusión, todas las otras prácticas semióticas [...] actúan como mensajes de silencio y de muerte.

\section{Y Flavia Soldano dice de Alberto Szpunberg:}

Estar en su letra como un mirlo en la palabra. ¿Qué silba en su poesía? Szpunberg no escribe sobre el papel, escribe en aire, escribe la luz, el sonido, el mirlo. Escribe el gesto del ritmo que pliega la resonancia en la frase, la imagen que nos mueve en la rama y el silencio anidando Enel mirlo como en el poema "Adivinanza":

Ni siquiera la palabra mirlo puede ser el silbido del mirlo, 
ni siquiera la belleza entre sus sombras de decirlo, no solo esa cadencia en el balanceo de las ramas, sino el silencio al oído que anida en la palabra mirlo para que el silbido sea solo solamente mirlo: ¿es el temblor de las sílabas únicas en los labios la claridad del aire como si sus alas me rozaran?

Héctor Miguel Angeli (1930) nos dice em una entrevista: "Cada poema es un edificio donde un ladrillo de más o de menos atenta contra su equilibrio".

Nicolás Rosa había destacado que

La poesía de cada poeta está ordenada, en primer lugar y como debe ser, por la vida: una vida donde lo "estético" siempre ha sido el resultado último del sufrimiento de la falta como despojo en lo real; después, por una escritura tan larga como la vida misma, tan pegada a ella que solo puede ser formulada como destino [...] Combustiones alucinantes.

Y, corriendo el riesgo de caer en un catálogo o en las famosas "guías telefónicas" de algunas antologías, no puedo dejar de mencionar a Oscar del Barco (1928). Al excelente, casi secreto, aunque cas vez se hace escuchar más, Aldo Oliva (1927-2000), rescatando hace apenas 15 años (que con del Barco y Luis Benítez, por caminos diferentes, contribuyeron a darle a Juan L. Ortíz una nueva dimensión) y a abrir posibilidades de lecturas, muy actuales, de una poesía del más alto nivel, dotándola de una juventud codiciable.

El salteño Jacobo Regen (1935), otra voz refinada, ha sabido aunar las múltiples dimensiones proporcionadas por las variadas vertientes de su formación cultural. Y Marcos Silber (1934) quien, con su intensidad poética, nos hace encontrar siempre, Un destello en la noche / En el cielo de la noche.

Hay muchos otros poetas que quisiera nombrar, porque me hubiera gustado incluirlos, pero es imposible dada la limitación inicial de once poetas que tiene la antología. Vaya entonces como una especia de disculpas la mención de Carlos Aprea, Cristina Aliaga, Luis Arganaraz, María Teresa Andruetto, Adela Basch, Manuel Bendersky, Luis Benítez, Jorge Bocanera, Daniel
Calmels, César Cantoni, Marta Ciewlong, Dolores Etchecopar, Héctor Freire, Celia Fontán, Javier Galarza, Hilda Guerra, Juan Fernando García, Nora Hall, Liliana Lukin, Claudia Masin, Eduardo Milleo, Vicente Muleiro, Marta Ortíz, Graciela Perosio, Víctor Redondo, Rogelio Ramos Signes, Mario Sampaolesi, Mónica Sifrim, Marcos Silber, Víctor Redondo, Rolando Rebagliatti, Hugo Rivella, Mercedes Roffé, Hugo Savino, Alejandro Schmidt, Patricio Torne, Beatriz Vignoli, Susana Villalba. Cada uno con una voz peculiar, agregando algo al mundo.

Y aun así quisiera seguir nombrando a los poetas más jóvenes, una mayoría de los cuales no pertenece a la Ciudad Autónoma de Buenos Aires sino que cada uno/a va moviendo con su palabra "los centros geográficos"; por ejemplo, Carlos Aldazábal, Jotaele Andrade, Anahí Lazaroni, Gustavo Caso Rosendi (que combatió en Malvinas y nos legó su libro Soldados, entre varios), Eduardo Rezzano, Sandra Cornejo, Paula Jiménez España, Gabriel Franco, María Malusardi, María Laura Prelooker, Lidia Rocha, Nancy Toselli, y tantos otros haciendo desde donde están el centro del mundo, pues al vaivén de la producción poética es centrífugo y centrípeto al mismo tiempo.

La poeta Laura Estrin nos dice:

Escribir poesía pasa a ser un trato con el nombre de las cosas: nombrar las cosas para tenerlas, fina saciedad del que escribe fragmentos [...] Escribir es un terrible malentendido permanente con los otros, Malentendida que se acrecienta y que nada pueda atenuar $[\ldots]$

\section{Y Hugo Savino:}

Es hora de aceptar que las grandes obras se escuchan en uno, se procesan, se gustan en la boca, las inventamos en la mirada, se gestualizan, se usan para vivir (y) esa actividad loca es su historicidad [...] Uno escribe como yéndose a cada momento pero a la vez, resistiendo, esperando que la palabra más propia ocurra $[\ldots]$

Quisiera recordar unas palabras de Georges Bataille, que se despliegan casi como un oxímoron: 
El fracaso de la literatura por medio del ejercicio implacable de la literatura. Por ello se trata de un juego mortal: porque es imposible, y ha dejado por tanto de ser un juego. Es un testimonio personal, cuya grandeza emana del desgarramiento y de su poder poético, y la inspiración de la combinatoria libertad-exceso, que desemboca en la nada.

Como puede observarse, una de las tareas de la poesía es cumplir el suplicio de Sísifo, donde lo único verdadero es el recomienzo.

Finalmente, decir que Argentina es un país de una inmensa riqueza poética. Es ese su "Estado de gracia" y de transformación permanente, como nos lo muestra Susy Shock -escritora distinguida por la Legislatura de la Ciudad Autónoma de Buenos Aires- en este poema:

En el mar de tus formas

mis manos enredaderas se deforman, nunca serán binarias, no, nunca.

A veces, te o me masculinizan

y otras, féminas de algas, te inventan el sueño, a veces, son animal araña

o bestia pajarito, o a veces agotadas de tanta biología, son simplemente éter, o centrífugo luz, o vino tinto cósmico, ponele. Ayer, por ejemplo, ¿te acordás?, fuimos lágrima, ¡ay!, ese rato de llorarnos el cuerpo, el sudor, el gemido, el ardor y al instante, madres tierra de nuestro abismo. 


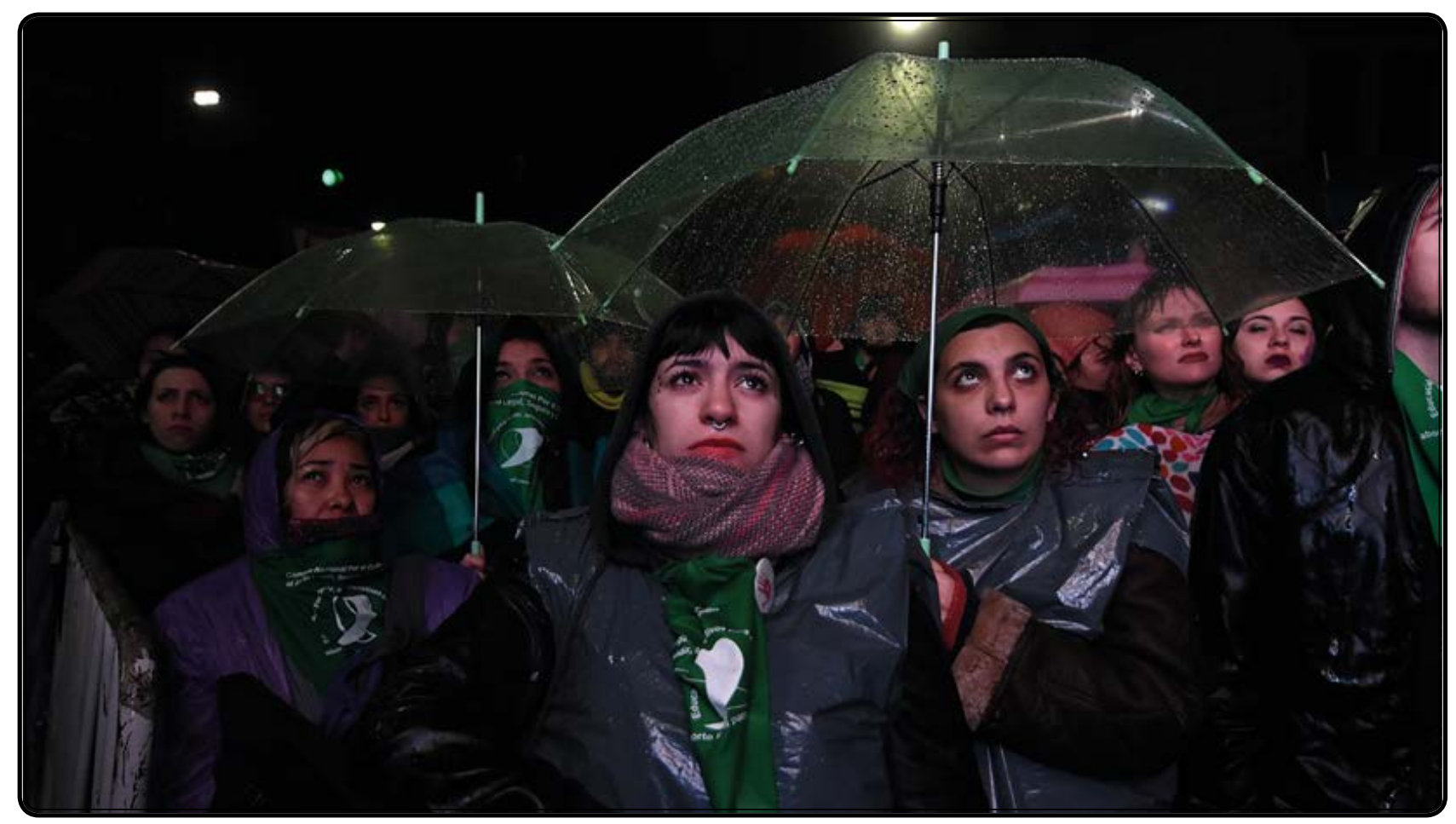

Seguir, persistir, no desistir. 